\title{
Design of a Continuous Passive Motion (CPM) Machine for Wrist Joint Therapy
}

\author{
Antonius Hendro Noviyanto ${ }^{1}$, Laurentia Deby Septilianingtyas ${ }^{2}$, Dita Rahmawati ${ }^{3}$ \\ 1,2,3 Department of Electromedical Engineering, Politeknik Mekatronika Sanata Dharma, Yogyakarta, Indonesia \\ Email: ${ }^{1}$ hendro@pmsd.ac.id, ${ }^{2}$ laurentia807@gmail.com, ${ }^{3}$ rahmawatidita88@gmail.com
}

\begin{abstract}
Patients after joint surgery require passive movements that are carried out continuously. The movement is given to the patient to reduce the stiffness that occurs in the joints after joint surgery. Joint stiffness is characterized by pain and limited motion of the joint, which is caused due to reduced synovial fluid. Synovial fluid in the joints can be reduced if the joint is not moved in a long time. This research will design a wrist joint therapy machine that can be moved flexion, extension, ulnar and radial. Besides that, the device to be designed can be adjusted the angle of movement of the tool and the speed of movement of the tool. The angles of movement that can be reached are: (1) flexion movement: $80^{\circ}$ movement angle, (2) extension movement: $75^{\circ}$ movement angle, (3) radial movement: $25^{\circ}$ movement angle, and (4) ulnar movement: movement angle $39^{\circ}$. Adjustable speeds include: 1 RPM, 2 RPM and 3 RPM. In the result of testing device, we find the maximum difference of movement in $2^{\circ}$ and the speed of rotation we have the difference in 0.5 second. Based on experiments that have been done, the tool can be controlled in accordance with the desired movement settings.
\end{abstract}

Keywords- CPM Machine, Wrist, Joint Stiffness, Rehabilitation, Microcontroller

\section{INTRODUCTION (HEADING 1)}

Continuous Passive Motion (CPM) Machine is a device that used for help patients to move the joints [1][2][3][4][5]. Passive and continuous movements which generated by CPM Machine can help out patient after joint surgery during doing the rehabilitation to restore joint movement [5][6][7].

Patient post joint surgery or post joint trauma, require long rest and make minor movement in the joint. Minor movement in the joint can be helped by a device that can moved passively and continuously. Thus, with passive and continuous movement can restore joint limitations or joint stiffness in patient post joint surgery [8][9][10][11].

Joint stiffness can be marked with pain in the joint and limitation movement on the joint. Joint stiffness can be caused by joint capsule adhesions with cartilage in the surrounding joint. Joint adhesions caused by occurrence of decline synovial fluids around the joint [12]. Synovial fluids are the liquid which used to lubricant on the joint. Decreased synovial fluids on the joint are caused by the joint didn't be move after joint surgery.

Joint stiffness in patient post joint surgery can be prevented by providing movement exercise that can restore limitation movement on the joint [13][14]. These exercise can be done by providing passive and repetitive movements. Passive movements are movements that do not require muscle work. Movements exercise can be done using CPM Machine. In accordance with its working principle, CPM Machine can move the joints passively and continuously. Besides that, movements exercise with CPM machine can reduce bleeding that occurs and increase synovial fluid on around the joint [15]. Using CPM machine has the following benefits [16]:

1) Increases nutrition and metabolic activity on the surface of cartilage.

2) Stimulates mesenchymal cells into differentiation in the surface of cartilage.

3) Increases recuperation of cartilage and periarticular tissue, such as tendons and ligaments.

The scope of motion from the wrist joint are flexion, extension, ulnar (adduction), radial (abduction) and circular movements [17][18]. Weight of adult human hands can be calculated $0.7 \%$ of the total weight of the human body [19].

In other research [13], has conducted research on the CPM Machine which is used to perform therapy in the shoulder joint. Where the tool is also used to support the arm and help to move passively and continuously. The torque requirement of the tool affects the performance of the tool.

In other research [20][21], has conducted research on therapeutic tools that can be used to perform passive therapy and active therapy on the hands. In this study, a therapy device that is driven by a DC motor is designed.

In other research [22], has conducted research on rehabilitation equipment using pneumatic parallel manipulator. This tool is developed using pneumatic technology, which utilizes compressed air and features a parallel manipulator that is used for movement of the human wrist joint.

In other research [23], this paper focuses on robots for wrist rehabilitation designed to provide three degrees of rotational freedom: abduction-adduction; flexion-extension; pronation-supination.

There are many other studies that develop rehabilitation equipment [24][25], of these tools are mostly used for rehabilitation of the upper limb and have a large size.

In this study, we will discuss design of the CPM Machine therapy that can be used for wrist therapy. Where the movement of the tool will be controlled using a microcontroller. The microcontroller in this tool will control 
the movement of the stepper motor which functions as a source of movement for the wrist. The movements that will be carried out in this design include [23][26][27][28]:

1) Flexion movement with a maximum angle of motion of $80^{\circ}$,

2) Extensions movement with a maximum angle of movement of $75^{\circ}$,

3) Radial movement with a maximum angle of movement of $25^{\circ}$, and

4) Ulnar movement with a maximum angle of motion of $39^{\circ}$ at the wrist joint.

The limit of the person's body weight to be used as the limit for calculating the torque from the hand is $80 \mathrm{~kg}$ and length is $20 \mathrm{~cm}$.

The results of designing the CPM Machine for the wrist joint will be presented in four parts. First, the research will present the needs and benefits of the CPM Machine therapy device. Second, this research will describe the stages in the design of the CPM Machine therapy device, such as the calculation of the required torque and the calculation of the conversion from the rotary encoder sensor to the angle of the device. Third, this study will discuss and analyze the test results from the design of the CPM Machine therapy device. The test will be carried out 3 times, so that the accuracy of the designed tools will be known. Fourth, this study will provide a discussion and conclusions from the results of the design of the CPM Machine therapy device that has been carried out.

\section{METHODS}

In this research using the ATmega328 Microcontroller as controller of the system and use the Nema 23 stepper motor as a drive for the wrist joint. In the device that designed using the Nextion NX4024T032 LCD for the interface between user and device, and also as an information viewer of the device.

The use of the Nema 23 stepper motor on this research is based on the torque requirements of the requirements used to move the wrist. To control the Nema 23 stepper in this design using micro stepping controllers. Micro stepping can be used to increase the resolution of the stepper motor used [29]. The torque from the hand can be calculated with the following equation [30]:

$$
\tau=m \times g \times 1 / 2 l
$$

where :

$$
\begin{aligned}
\tau & =\text { torque }(\mathrm{Nm}) \\
\mathrm{W} & =\text { force }(\mathrm{N}) \\
1 & =\operatorname{lenght}(\mathrm{m}) \\
\mathrm{m} & =\text { mass }(\mathrm{kg}) \\
\mathrm{g} & =\text { acceleration of gravity }\left(\mathrm{m} / \mathrm{s}^{2}\right)
\end{aligned}
$$

So, that it can be seen the torque from the hand is as follows:

$$
\begin{aligned}
\tau & =m \times g \times 1 / 2 l \\
\tau & =\frac{0.7}{100} \times 80 \times 10 \times \frac{1}{2} \times 0.2 \\
\tau & =0.56 \mathrm{Nm}
\end{aligned}
$$

Based on the desired needs, then designed a device that can meet for wrist therapy. Box from the device will be made from acrylic with the design as in following figure 1:

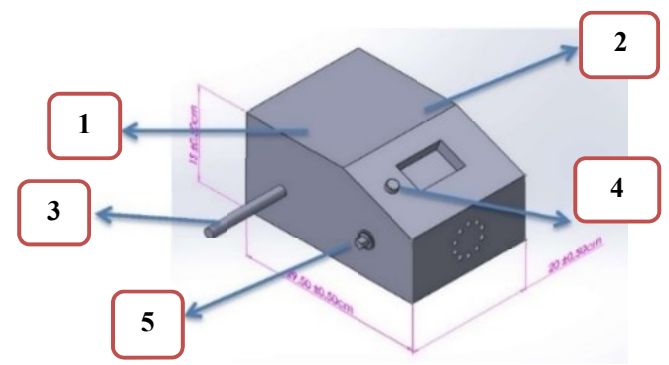

Fig 1. Tool Box Design

TABLE 1. DESCRIPTION OF TOOL BOX PARTS

\begin{tabular}{|c|l|l|}
\hline No. & \multicolumn{1}{|c|}{ Part } & \multicolumn{1}{c|}{ Description } \\
\hline 1. & Box & $\begin{array}{l}\text { As a place for the main and supporting } \\
\text { components }\end{array}$ \\
\hline 2. & LCD Touchscreen & As a tool interface \\
\hline 3. & Arm Support & As a support arm during therapy \\
\hline 4. & Emergency & $\begin{array}{l}\text { To stop the therapy process when there } \\
\text { is a disturbance }\end{array}$ \\
\hline 5. & Motor Shaft & $\begin{array}{l}\text { As a connector between the motor and } \\
\text { the wrist mount }\end{array}$ \\
\hline
\end{tabular}

In a device equipped with a hand support that is used to support the hand during therapy, the design of the hand support is as shown in Figure 2.

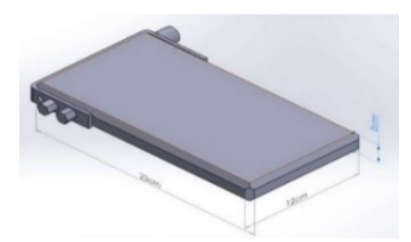

(a)

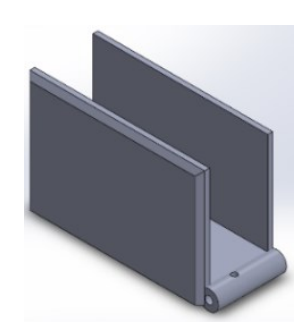

(b)

Fig 2(a). Flexion-Extension Movement Hand Support and 2(b). UlnarRadial Movement Hand Support

The system designed on the tool will be controlled by a microcontroller. The microcontroller will receive input from the limit switch which is used to indicate the maximum position, minimum position, and middle position of the tool movement. Besides receiving input from the limit switch, the microcontroller also receives input from the LCD in the form of determining the type of movement, the angle of movement, and the speed of the therapy movement. There is also a rotary encoder sensor which is used to determine the angle of movement of the tool. The output signal of microcontroller 
will used the motor driver to drive the stepper motor [31]. Block diagram of the tool as in Figure 3.

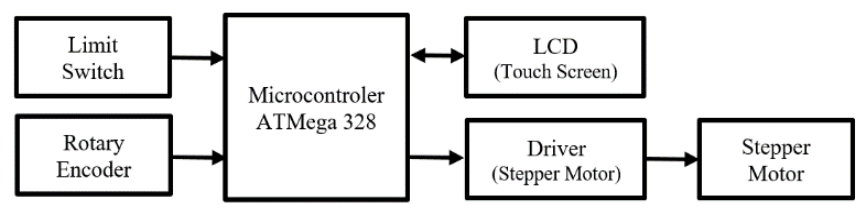

Fig 3. Blog Diagram of System

The calculation of the conversion of the signal generated by the rotary encoder sensor into the amount of rotation angle can be done with the following equation 2 :

$$
\text { angle }=\frac{x}{n} \times 360^{\circ}
$$

where:

$\mathrm{x}=$ The number of pulses required by the rotary encoder for one turn

$\mathrm{n}=$ the number of pulses generated by the rotary encoder

The test method used in this research is to test 3 times and make comparisons with existing measuring instruments. The test is carried out at the angle of movement of the tool and at the rotational speed of the tool. Testing the angle of movement of the tool is done by comparing the results of the angle reading by the microcontroller with the angle reading from the protractor. Testing of the rotational speed of the tool is done by comparing the length of play time of the tool being tested using a timer by a stop watch

\section{RESUlTS AND TESTING}

In accordance with the design that has been carried out in this study, it produces hardware tools as in Figure 4 below.

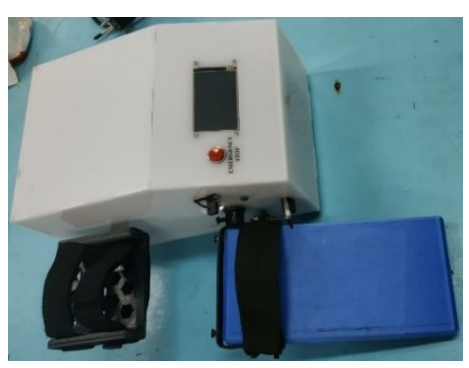

Fig 4. Generated Tool

Tests carried out on this tool are carried out on testing the angle of movement of the tool and testing the movement speed of the tool. The test is carried out according to the method described in the second part of this study.

\section{A. Testing Tool Movement Angle}

Testing the angle of movement of the tool is carried out three times, the results of the first test are recorded in table 2, the second test results are recorded in table 3, and the third test results are recorded in table 4.

TABLE 2. Test Results 1 Angle Of The Tool Movement

\begin{tabular}{|c|c|c|}
\hline \multirow[b]{2}{*}{$\begin{array}{l}\text { Angle Specified } \\
\text { (in degrees) }\end{array}$} & \multicolumn{2}{|c|}{ Experiment 1} \\
\hline & $\begin{array}{l}\text { Motor Pulse } \\
\text { Calculation }\end{array}$ & $\begin{array}{c}\text { Motor Angle } \\
\text { Readout } \\
\text { (in degrees) }\end{array}$ \\
\hline 0 & 0 & 0 \\
\hline 5 & 44 & 5 \\
\hline 10 & 89 & 9 \\
\hline
\end{tabular}

\begin{tabular}{|l|l|l|}
\hline 15 & 133 & 14 \\
\hline 20 & 178 & 18 \\
\hline 25 & 222 & 24 \\
\hline 30 & 267 & 30 \\
\hline 35 & 311 & 35 \\
\hline 40 & 356 & 39 \\
\hline 45 & 400 & 45 \\
\hline 50 & 444 & 50 \\
\hline
\end{tabular}

In table 2, we test the hardware about angle of movement. We measure the angle from $0^{\circ}$ to $50^{\circ}$. From the result of motor pulse, we can find the angle with equation (2). Based on the results of the first test shown in table 2 , there is a difference of $2^{\circ}$ when measuring $20^{\circ}$.

TABLE 3. Test Results 2 Angle Of The ToOl Movement

\begin{tabular}{|c|c|c|}
\hline \multirow{2}{*}{$\begin{array}{c}\text { Angle Specified } \\
\text { (in degrees) }\end{array}$} & $\begin{array}{c}\text { Motor Pulse } \\
\text { Calculation }\end{array}$ & $\begin{array}{c}\text { Motor Angle } \\
\text { Readout } \\
\text { (in degrees) }\end{array}$ \\
\cline { 2 - 3 } & 0 & 0 \\
\hline 0 & 44 & 4 \\
\hline 5 & 89 & 9 \\
\hline 10 & 133 & 15 \\
\hline 15 & 178 & 19 \\
\hline 20 & 222 & 25 \\
\hline 25 & 267 & 29 \\
\hline 30 & 311 & 34 \\
\hline 35 & 356 & 40 \\
\hline 40 & 400 & 45 \\
\hline 45 & 444 & 49 \\
\hline 50 & & \\
\hline & &
\end{tabular}

In table 3, same with table 2, we test the hardware about angle of movement. We measure the angle from $0^{\circ}$ to $50^{\circ}$. From the result of motor pulse, we can find the angle with equation (2). Based on the results of the second test shown in table 3 , there is a difference in the angle of $1^{\circ}$.

TABLE 4. Test Results 3 Angle Of The Tool Movement

\begin{tabular}{|c|c|c|}
\hline \multirow{2}{*}{$\begin{array}{c}\text { Angle Specified } \\
\text { (in degrees) }\end{array}$} & $\begin{array}{c}|c| \\
\text { Motor Pulse } \\
\text { Calculation }\end{array}$ & $\begin{array}{c}\text { Motor Angle } \\
\text { Readout } \\
\text { (in degrees) }\end{array}$ \\
\cline { 2 - 3 } & 0 & 0 \\
\hline 0 & 44 & 4 \\
\hline 5 & 89 & 9 \\
\hline 10 & 133 & 14 \\
\hline 15 & 178 & 19 \\
\hline 20 & 222 & 25 \\
\hline 25 & 267 & 29 \\
\hline 30 & 311 & 35 \\
\hline 35 & 356 & 40 \\
\hline 40 & 400 & 45 \\
\hline 45 & 444 & 50 \\
\hline 50 & & \\
\hline & & \multicolumn{2}{|c|}{} \\
\hline
\end{tabular}

In table 4, same with table 2 and table 3 , we test the hardware about angle of movement. We measure the angle from $0^{\circ}$ to $50^{\circ}$. From the result of motor pulse, we can find the angle with equation (2). Based on the results of the third test shown in table 4 , there is a difference in the angle of $1^{\circ}$. 
Based on the data from the test results, the angle of movement of the tool is obtained that corresponds to the angle of movement needed for the tool. From table 2, the angle of movement has a maximum difference of $2^{\circ}$.

\section{B. Testing of Tool Movement Speed}

The motion speed test of the tool is done by measuring the length of time the tool moves. Time calculation is done using a stop watch tool. Tests carried out three times data collection. The test steps are carried out as follows:

1) The 1 RPM test is done by measuring the length of time one full rotation of the instrument being tested.

2) The 2 RPM test is done by measuring the length of time two full turns of the instrument being tested.

3) The 3 RPM test is done by measuring the length of time three times the full rotation of the instrument being tested.

Based on the tests that have been done, the results are as in table 5 .

Table 5. Results Of The Testing Speed Of The Tool

\begin{tabular}{|c|c|c|c|}
\hline RPM & Experiment 1 & Experiment 2 & Experiment 3 \\
\hline 1 & 59.50 & 59.56 & 59.58 \\
\hline 2 & 59.58 & 59.56 & 59.57 \\
\hline 3 & 59.80 & 59.50 & 59.30 \\
\hline
\end{tabular}

Based on the results of the tests that have been carried out, it can be seen that the results are close to the predetermined needs. The need for 1 RPM in experiments I, II, and III, it was found that the movement time in one rotation was 59.5 seconds. Needs of 2 RPM in experiments I, II, and III, it was found that the movement time in one rotation was 59.5 seconds. Needs of 3 RPM in experiments I, II, and III obtained the duration of movement in three rotations is 59.5 seconds.

\section{DISCUSSION AND CONCLUSION}

Joint therapy is an activity used to increase the range of motion of the joints after joint surgery. Patients after joint surgery will feel pain in moving the joints, this results in patients experiencing joint stiffness due to reduced synovial fluid in the joints.

Joint stiffness can be reduced by performing passive, continuous light motion exercises on the joints. This motion exercise aims to increase the range of motion of the joints. Motion exercises can be performed according to the range of motion of the joints experiencing stiffness.

Passive and continuous light motion exercises can be assisted by a Continuous Passive Motion Machine therapy device. The CPM Machine tool in this study can be used with the desired motion settings, such as: the desired range of motion, the desired angle of motion, and the desired speed of movement.

In general, the data generated from the tests that have been carried out are in the conditions that are desired. The tool can work according to the selection of the desired joint range of motion, the desired angle of motion, and the desired speed of movement.

\section{REFERENCES}

[1] Mujianto, Cara Cepat Mengatasi 10 Besar Kasus Muskuloskeletal dalam Praktik Klinik Fisioterapi. Jakarta: CV. Trans Info Media, 2013.

[2] M. K. Saputra and A. A. Iskandar, "Development of automatic continuous passive motion therapeutic system," Proc. - Int. Conf. Instrumentation, Commun. Inf. Technol. Biomed. Eng. 2011, ICICIBME 2011, no. November, pp. 376-379, 2011.

[3] Y. Fu, F. Zhang, S. Wang, and Q. Meng, "Development of an embedded control platform of a continuous passive motion machine," IEEE Int. Conf. Intell. Robot. Syst., pp. 1617-1622, 2006.

[4] W. K. Song and J. Y. Song, "Improvement of upper extremity rehabilitation Robotic Exoskeleton, NREX," 2017 14th Int. Conf. Ubiquitous Robot. Ambient Intell. URAI 2017, pp. 580-582, 2017.

[5] J. C. Gose, "Continuous passive motion in the postoperative treatment of patients with total knee replacement. A retrospective study," Phys. Ther., vol. 67, no. 1, pp. 39-42, 1987.

[6] B. J., Surgical Anatomy of the Shoulder and Neck Region. Philadelphia: W.B. Saunders Co, 1972.

[7] H. N. Rasyid, R. M. Tati, S. Soegijoka, and J. T. Pramudito, "Design and realization of personal computer-based continuous passive motion device to prevent shoulder joint stiffness," pp. 573-576, 2004.

[8] S. Uetsuji, N. Kingsuvangul, B. Boonyasurakul, and W. Charoensuk, "Hand exoskeleton for continuous passive motion postoperative rehabilitation," BMEiCON 2017 - 10th Biomed. Eng. Int. Conf., vol. 2017-Janua, pp. 1-5, 2017.

[9] S. Dubey et al., "Semi-automatic continuous passive motion physiotherapeutic device for post stroke patients," Proc. Int. Conf. Circuits, Commun. Control Comput. I4C 2014, no. November, pp. 169-172, 2014.

[10] M. Tagami and Y. Tagawa, "Development of a continuous-passivemotion device with an active training mode for muscle recovery," 2017 Asian Control Conf. ASCC 2017, vol. 2018-Janua, no. Dialin 732, pp. 2226-2231, 2018.

[11] N. Hogan et al., "Motions or muscles? Some behavioral factors underlying robotic assistance of motor recovery," J. Rehabil. Res. Dev., vol. 43, no. 5, pp. 605-618, 2006.

[12] S. W. O'Driscoll and N. J. Giori, "Department of Veterans Affairs Continuous passive motion (CPM) : Theory and principles of clinical application,” J. Rehabil. Res. Dev., vol. 37, no. 2, pp. 179-188, 2000.

[13] S. Miyaguchi, K. Nojiri, N. Matsunaga, and S. Kawaji, "On effective movement in CPM for shoulder joint," in Conference Proceedings IEEE International Conference on Systems, Man and Cybernetics, 2008, pp. 530-534.

[14] S. Miyaguchi, N. Matsunaga, K. Nojiri, and S. Kawaji, "Impedance control of CPM device with flex-/extension and pro-/supination of upper limbs," in IEEE/ASME International Conference on Advanced Intelligent Mechatronics, AIM, 2007.

[15] K. Nojiri, N. Matsunaga, and S. Kawaji, "Inverse Kinematics Analysis," Int. Conf. Mechatronics, no. May, pp. 8-10, 2007.

[16] Selter R., Continuous Passive Motion (CPM): Textbook of Disoders and Injuries of the Musculoskeletal System. USA: Lippincott Williams \& Wilkins, 1999.

[17] J. Hamill and K. M Knutzen, Biomechanical Basis of Human Movement, 3rd ed. Lippincott Williams \& Wilkins, 2009.

[18] Y. J. W. Clauser C. E., McConville J. T., Weight, Volume, And Center Of Mass Of Segments Of The Human Body. Virginia: National Technical Information Service, Springfield, 1969.

[19] D. C. Giancoli, Physics Principles with Applications, 6th ed. United States of America: Pearson Education Inc., 2015.

[20] B. Birch, E. Haslam, I. Heerah, N. Dechev, and E. J. Park, "Design of a continuous passive and active motion device for hand rehabilitation," in Proceedings of the 30th Annual International Conference of the IEEE Engineering in Medicine and Biology Society, EMBS'08 - "Personalized Healthcare through Technology," 2008, pp. 4306-4309.

[21] J. Li, R. Zheng, Y. Zhang, and J. Yao, "iHandRehab: An interactive hand exoskeleton for active and passive rehabilitation," IEEE Int. Conf. Rehabil. Robot., no. 50975009, 2011. 
[22] M. Takaiwa and T. Noritsugu, "Development of wrist rehabilitation equipment using pneumatic parallel manipulator," Proc. - IEEE Int. Conf. Robot. Autom., vol. 2005, no. April, pp. 2302-2307, 2005.

[23] H. I. Krebs et al., "Robot-aided neurorehabilitation: A robot for wrist rehabilitation," IEEE Trans. Neural Syst. Rehabil. Eng., vol. 15, no. 3, pp. 327-335, 2007.

[24] T. Faculty and B. Co, "Application of Rubber Artificial Muscle Manipulator,” pp. 112-117, 1996.

[25] K. Koyanagi, J. Furusho, U. Ryu, and A. Inoue, "Development of rehabilitation system for the upper limbs in a NEDO project," Proc. IEEE Int. Conf. Robot. Autom., vol. 3, pp. 4016-4022, 2003.

[26] V. Squeri, L. Masia, L. Taverna, and P. Morasso, "Improving the ROM of wrist movements in stroke patients by means of a haptic wrist robot," Proc. Annu. Int. Conf. IEEE Eng. Med. Biol. Soc. EMBS, pp. 1268-1271, 2011.

[27] A. Erwin, M. K. O’Malley, D. Ress, and F. Sergi, "Kinesthetic Feedback during 2DOF Wrist Movements via a Novel MR-
Compatible Robot," IEEE Trans. Neural Syst. Rehabil. Eng., vol. 25, no. 9, pp. 1489-1499, 2017.

[28] R. Colombo et al., "Robotic techniques for upper limb evaluation and rehabilitation of stroke patients," IEEE Trans. Neural Syst. Rehabil. Eng., vol. 13, no. 3, pp. 311-324, 2005.

[29] W. Kim, D. Shin, and C. C. Chung, "Microstepping with nonlinear torque modulation for permanent magnet stepper motors," IEEE Trans. Control Syst. Technol., vol. 21, no. 5, pp. 1971-1979, 2013.

[30] C. C. Norkin and D. J. White, Measurement of Joint Motion: A Guide to Goniometry, Third Edition. F.A. Davis, 2009.

[31] S. Dorin-Mirel, I. Lita, and M. Oproescu, "Comparative analysis of stepper motors in open loop and closed loop used in nuclear engineering," 2017 IEEE 23rd Int. Symp. Des. Technol. Electron. Packag. SIITME 2017 - Proc., vol. 2018-Janua, pp. 357-360, 2017. 